\title{
Evaluation of Effect of Disinfection Systems on Bond Strength of Root Canal Sealers
}

\author{
Fatih. Çakıcı ${ }^{1}$ Elif Bahar Çakıc1 ${ }^{1}$, Alper İlker ${ }^{2}$, Hüseyin Sinan Topçuoğlu ${ }^{3}$ \\ ${ }^{1} \mathrm{PhD}$, Department of Endodontics, Faculty of Dentistry, Ordu University, Ordu, Turkey \\ ${ }^{2}$ Dr. Private dental clinics, Ordu, Turkey \\ ${ }^{3} \mathrm{PhD}$, Department of Endodontics, Faculty of Dentistry, Erciyes University, Kayseri, Turkey \\ Received: 19 March 2019, Accepted: 04 April 2020, Published online: 30 April 2020 \\ (C) Ordu University Institute of Health Sciences, Turkey, 2020
}

\begin{abstract}
Objective: The aim of this in vitro study is to evaluate and compare the effects of different disinfection methods ( $\mathrm{NaOCl}$ irrigation, $\mathrm{CHX}$ irrigation, laser, $\mathrm{PDT}$ ) on the bond strength of different root canal sealers (AH Plus sealer, MTA Fillapex, EndoSequence BC Sealer ).

Methods: In this study, one hundred and twenty extracted human mandibular premolar teeth were used. The teeth were randomly divided into 3 experimental groups and 12 subgroups using the website ( 3 different sealers and 4 different disinfection methods). Two slices were obtained from apical part, middle part and coronal part of each root. The push-out test was performed on each slice with a universal test machine. The maximum load applied to the filling material before failure was recorded in Newtons $(\mathrm{N})$ and converted to megapascals (MPa). Data were subject to Kruskal- Wallis test. Mann- Whitney U test was used for pairwise comparison with bonferroni correction. Significance level was set at a $=0.05$
\end{abstract}

Results: Kruskal Wallis test indicated that there were significant differences among the sealer groups for apical $(\mathrm{p}=0,000)$ and middle sections $(\mathrm{P}=0,001)$, and coronal sections $(\mathrm{P}=0,000)$.

Conclusion: Under the study limitation; the bonding strength of root canal sealers is influenced by disinfection methods.

Key words: AH Plus, EndoSequence BC Sealer, MTA Fillapex, Laser, Photodynamic treatment.

Suggested Citation: Cakici F, Cakici EB, Ilker A, Topcuoglu HS. Evaluation of effect of disinfection systems on bond strength of root canal sealers. Middle Black Sea Journal of Health Science, 2020; 6(1): 92-98

Address for correspondence/reprints:

Fatih Çakıcı

Telephone number: +90 (553) 9791598

ORCID-ID 0000000281472661

E-mail: dt_fatihcakici@hotmail.com

DOI: $10.19127 / \mathrm{mbsjohs.706381}$

\section{Introduction}

The success of root canal treatment depends on preparation, disinfection, and obturation stages. Various disinfection methods are used in endodontics. $\mathrm{NaOCl}$ irrigation is the commonly used method for disinfection of root canal system. It has capability of biofilm eradication, elimination of microorganisms and organic tissue dissolution (Haapasalo et al. 2014). However, it has some disadvantages such as tissue necrosis, ecchymosis, and paraesthesia or even life-threatening accidents (Zhu et al. 2013). The other irrigation solution is Chlorhexidine gluconate (CHX). It has several properties such as wide range of antimicrobial 
activity, less toxic effect than $\mathrm{NaOCl}$, and reasonable clinical performance (Gomes et al. 2013). Nonetheless, both of these irrigation solutions are not able to disinfect the root canal system completely. So, scientists suggested new methods. The first one is Photodynamic therapy (PDT). It uses the light with a specific wavelength to activate a photosensitizing dye (metilen blue, toluidine blue, and photosensitizer) in the presence of oxygen. Recently studies have confirmed that PDT has bactericidal potential against to Enterococcus Faecalis. The second method is laser root canal irradiation. This method eradicates microorganism from accessory side canals, isthmus, and unprepared area (Plotino et al. 2019).

Various obturation materials have been defined in endodontics. AH Plus sealer (Dentsply Maillefer, Ballaigues, Switzerland) is an epoxy resin-based sealer and has some properties such as low solubility, sufficient viscosity, dimensional stability, and longer setting time (Versiani et al. 2006; Souza et al. 2009).

MTA Fillapex (Angelus Industria de Produtos Odontologicos S/A, Londrina, Brazil) with properties of good sealing ability, low solubility, biocompatibility, bactericidal effect, and low setting expansion, has been introduced based on calcium silicate in endodontics (Gurgel-Filho et al. 2014; Mestieri et al. 2015). It is presented in the form of two pastes. Recently, EndoSequence BC Sealer (Brasseler USA, Savannah, GA), a bioceramic sealer based on calcium silicate composition, has been presented in endodontics. It has properties such as dimensional stability, good flow ability, premixed, and injectable paste containing water-free thickening vehicles (Jafari and Jafari 2017; Lee et al. 2017).

The effects of different irrigation solutions on the bond strength of root canal sealers were evaluated in several studies. However, there are not enough sources in the literature for validating this data. The effects of PDT and laser disinfection methods on the push-out bond strength value of the epoxy resin and calcium silicate-based sealers are unknown. Thus, the aim of this in vitro study was to evaluate and compare the effects of different disinfection methods $(\mathrm{NaOCl}$ irrigation, CHX irrigation, laser, PDT) on the bond strength of different root canal sealers (AH Plus sealer, MTA Fillapex, EndoSequence BC Sealer).

\section{Methods}

In this study, one hundred and twenty extracted human mandibular premolar teeth, extraction reasons not related to this study, were used. Sample size calculated based on previous study (Cakici et al. 2016) After the external root surfaces of the teeth were cleaned with periodontal curettes, they were kept in distilled water until used. Access cavities were performed by diamond burs (Dimei Royal, Dimei Dental, Anyang, Henan, China) under water cooling then radiographies in bucco-lingully and mesio distally directions were taken. Exclusion criteria were multiple root and canals, calcified canals, internal and external resorptions, extensive root caries, having root canal treatments, root curvature more than 100 according to Schneider 1971 method, and apical diameter more than $10 \mathrm{~K}$ file.

Also, root surfaces were inspected with 2,5 magnification dental loop and roots having fractures and cracks were excluded from this study. Working lengths were determined as $1 \mathrm{~mm}$ beyond the apex by the aid of $10 \mathrm{~K}$ file (VDW, Munich, Germany). K3XF (SybronEndo, Orange, CA USA) rotary file system was used $3 \mathrm{Ncm}$ and $400 \mathrm{Rpm}$ in packing motions to prepare the root canals at full working length with a torque- control motor (X-Smart Plus, Dentsply Maillefer). The instrument sequence of the K3XF system was 10/25 (1/3 working length), 08/25, 04/40, $04 / 35,04 / 30$ (encountered resistance) then $04 / 25$ was used for final apical shaping. The root canals were irrigated with $2 \mathrm{~mL}$ sterile saline solution after each instrument. Each instrument was used for 3 times. The teeth were randomly divided into 3 experimental groups and 12 subgroups using the website (http://www.random.org) (figure1)

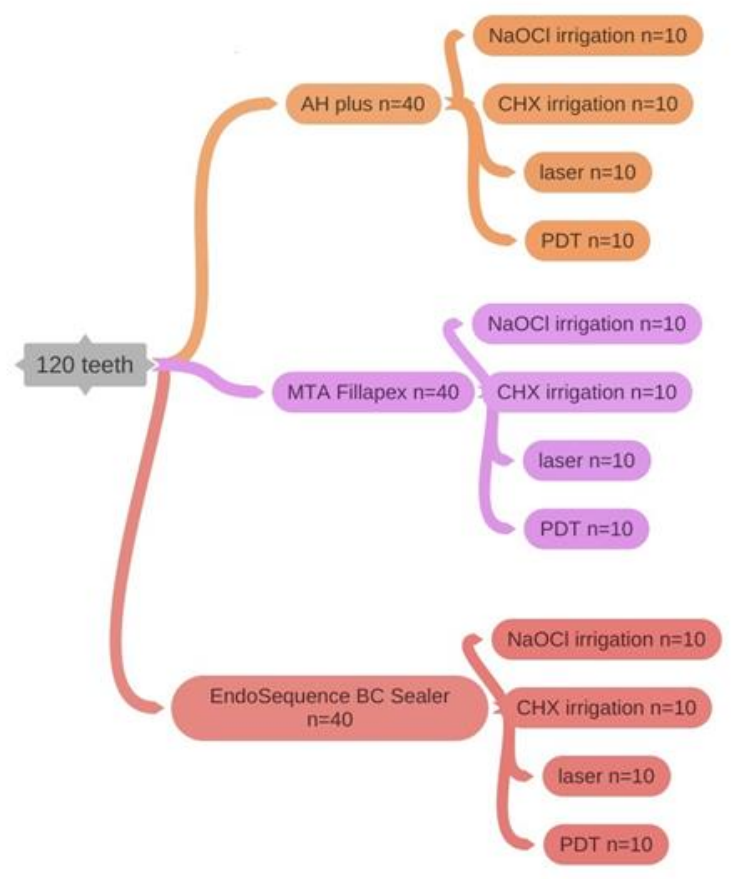

Figure 1. Design of the study 


\section{NaOCl irrigation gruops}

$3 \mathrm{ml}$ 17\% EDTA 1 minute, $3 \mathrm{ml} \mathrm{NaOCl} 1$ minute, and $5 \mathrm{ml}$ distilled water 1 minute was used for final irrigation procedure. Root canals were dried with absorbent paper points and obturated with the single cone technique using AH Plus sealer, MTA Fillapex, EndoSequence BC Sealers.

\section{CHX irrigation groups}

$3 \mathrm{ml} 17 \%$ EDTA 1 minute, $6 \mathrm{ml} 2 \%$ CHX 1 minute, and $5 \mathrm{ml}$ distilled water 1 minute was used for final irrigation procedure. Root canals were dried with absorbent paper points and obturated with the single cone technique using AH Plus sealer, MTA Fillapex, EndoSequence BC Sealer

\section{Laser gruops}

$3 \mathrm{ml}$ 17\% EDTA 1 minute, $3 \mathrm{ml} \mathrm{NaOCl} 1$ minute, and $5 \mathrm{ml}$ distilled water 1 minute was used for irrigation procedure. The Methylene blue solution was injected into the root canals using a sterile side port needle, and the Methylene blue was agitated using 04/25 K3XF file. Then Methylene blue had been activated with Nd:YAG laser(Deka smart file, DEKA, Italy) $200 \mu$ tip (1064 nm wave length 1,5 w $15 \mathrm{hz} 100 \mathrm{mj}$ ) for 1 minute. Finally, root canals had been cleaned $5 \mathrm{ml}$ distilled water for 1 minute. Root canals were dried with absorbent paper points and obturated with the single cone technique using $\mathrm{AH}$ Plus sealer, MTA Fillapex, EndoSequence BC Sealer.

\section{PDT groups}

$3 \mathrm{ml}$ 17\% EDTA 1 minute, $3 \mathrm{ml} \mathrm{NaOCl} 1$ minute, and $5 \mathrm{ml}$ distilled water 1 minute was used for irrigation procedure. Nd:YAG laser $200 \mu$ tip (1064 nmwave length $1,5 \mathrm{w} 15 \mathrm{hz} 100 \mathrm{mj}$ ) had been applied into the root canals for 1 minute. Root canals were dried with absorbent paper points and obturated with the single cone technique AH Plus sealer, MTA Fillapex, EndoSequence BC Sealer.

Remained gutta-percha and sealer were cleaned. The teeth were restorated with glass ionomer cement. All the samples had been stored at $370 \mathrm{C}$ and 100\% humidity for 2 weeks. Each root was sectioned perpendicularly to its long axis using a precision saw (Megatome t180 presi, Eybens, France) at a slow speed under water cooling. $1 \mathrm{~mm}$ from apical part of root was removed. Then two slices were obtained from each part of root apical, middle, and coronal. The push-out test was performed on each root with a universal test machine (AGS-X, Shimadzu Corporation, Tokyo, Japan) at a crosshead speed of 1 $\mathrm{mm}$ per minute. The maximum load applied to the filling material before failure was recorded in
Newtons $(\mathrm{N})$ and converted to megapascals (MPa). N and converted to MPa according to the following formula:

Push-out bond strength $(\mathrm{MPa})=$ maximum load $(\mathrm{N}) /$ adhesion area of root filling (A) (mm2).

\section{Statistical Analysis}

The descriptive analyses for the groups were calculated. The normality of the variation of the data was verified by the shapiro-wilk test $(\mathrm{P}<0,05)$. Data were subject to Kruskal- Wallis test. Mann- Whitney $\mathrm{U}$ test was used for pairwise comparison with bonferroni correction. The data were analyzed using IBM Statistical Package for the Social Sciences (SPSS Inc., Chicago, IL, USA) for Windows, version 20. Significance level was set at $\mathrm{P}=0,05$.

\section{Results}

Kruskal Wallis test indicated that there were significant differences among the sealer groups for apical $(P=0,000)$ and middle sections $(P=0,001)$, and coronal sections statistically $(\mathrm{P}=0,000)$.

For apical part of the root; there was statistically significant relationship between AH plus +laser disinfection group and MTA Fillapex + PDT disinfection group $(\mathrm{P}=0,000)$, EndoSequence $\mathrm{BC}$ Sealer +laser disinfection group $(\mathrm{P}=0,000)$, AH plus+ PDT disinfection group $(\mathrm{P}=0,000)$, MTA Fillapex +laser disinfection group ( $\mathrm{P}=0,006)$, MTA Fillapex + CHX disinfection group $(\mathrm{P}=0,025)$, EndoSequence BC Sealer CHX disinfection group $(\mathrm{P}=0,036)$. Also there was statistically significant relationship between EndoSequence BC Sealer + PDT disinfection group and MTA Fillapex + PDT disinfection group $(\mathrm{P}=0,007)$, EndoSequence $\mathrm{BC}$ Sealer +laser disinfection group $(\mathrm{P}=0,048)$, AH plus+ PDT disinfection group $(\mathrm{P}=0,045)$ (Table 1)(Figure 2). 


\section{Disinfection Systems on Bond Strength of Sealers}

Table 1. Median and standard deviation values of apical part of the root of the groups. Same letters indicate a statistical difference $(\mathrm{P}=0,05)$

\begin{tabular}{|c|c|c|c|c|}
\hline & $\mathrm{NaOCl}$ irrigation & $\begin{array}{l}\text { Laser } \\
\text { disinfection }\end{array}$ & $\begin{array}{l}\mathrm{CHX} \\
\text { Irrigation }\end{array}$ & $\begin{array}{l}\text { PDT } \\
\text { disinfection }\end{array}$ \\
\hline AH plus & $4,63 \pm 1,89$ & $7,69 \pm 2,40^{\mathrm{a}, \mathrm{b}, \mathrm{c}, \mathrm{d}, \mathrm{e}, \mathrm{f}}$ & $5,52 \pm 3,06$ & $2,21 \pm 2,85^{\mathrm{c}, \mathrm{h}}$ \\
\hline MTA Fillapex & $5,05 \pm 5,03$ & $3,52 \pm 3,36^{\mathrm{d}}$ & $3,97 \pm 2,13^{\mathrm{e}}$ & $3,03 \pm 2,04^{\mathrm{a}, \mathrm{g}}$ \\
\hline $\begin{array}{l}\text { EndoSequence BC } \\
\text { Sealer }\end{array}$ & $4,29 \pm 2,71$ & $2,78 \pm 2,32^{\mathrm{b}, \mathrm{h}}$ & $3,89 \pm 2,54^{\mathrm{f}}$ & $5,61 \pm 1,70^{\mathrm{g}}$ \\
\hline
\end{tabular}

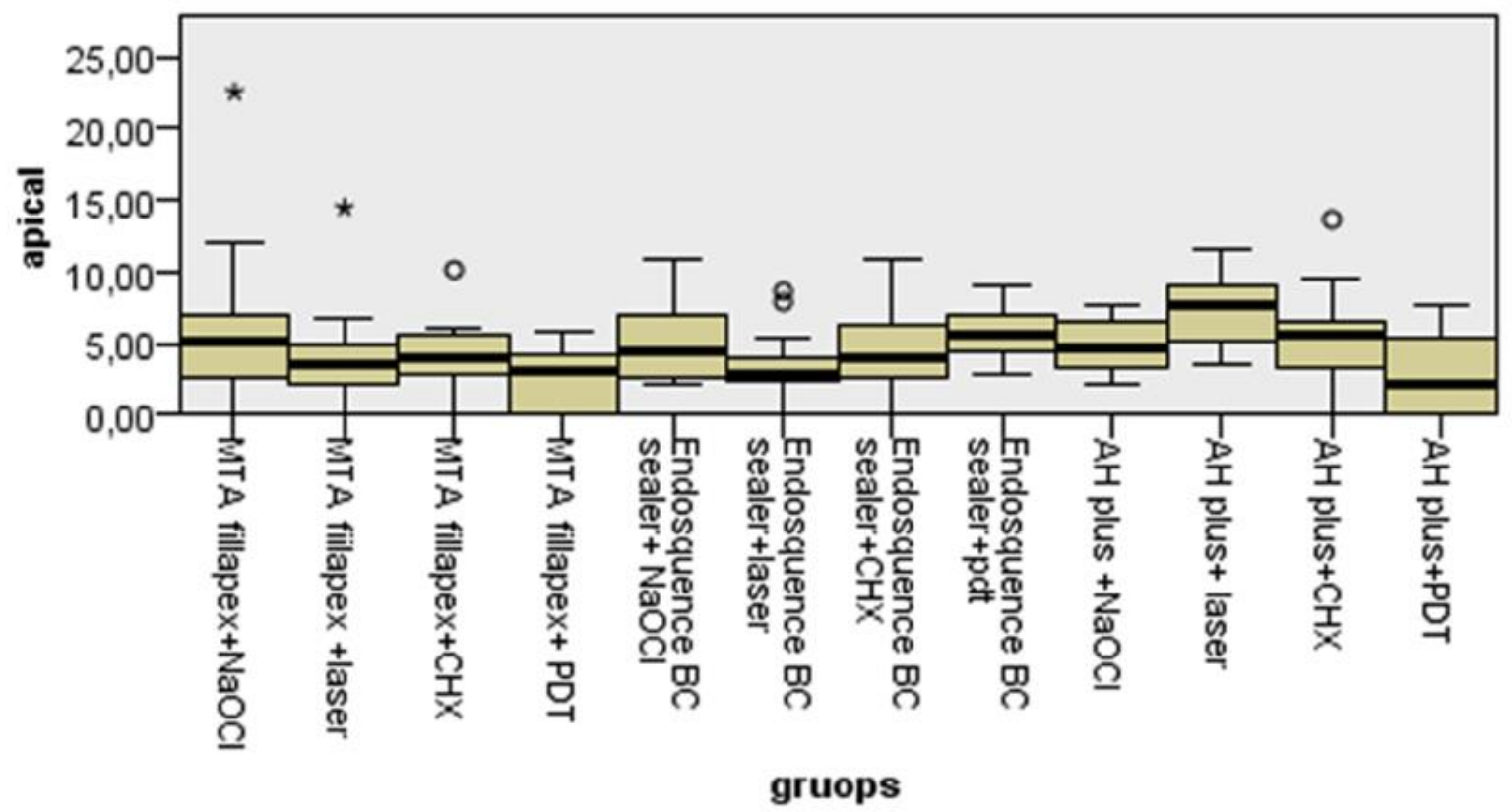

Figure 2. Mean rank value of groups for apical part of root

Table 2. median and standard deviation values of middle part of the root of the groups. Same letters indicate a statistical difference $(\mathrm{P}=0,05)$

\begin{tabular}{|c|c|c|c|c|}
\hline & NaOCl irrigation & $\begin{array}{l}\text { Laser } \\
\text { disinfection }\end{array}$ & $\begin{array}{l}\text { CHX } \\
\text { Irrigation }\end{array}$ & $\begin{array}{l}\text { PDT } \\
\text { Disinfection }\end{array}$ \\
\hline AH plus & $7,01 \pm 3,23$ & $7,24 \pm 2,83^{a}$ & $6,42 \pm 2,02$ & $5,53 \pm 3,14$ \\
\hline MTA Fillapex & $4,65 \pm 3,70^{a}$ & $3,55 \pm 2,64^{a}$ & $6,03 \pm 1,75$ & $3,37 \pm 1,64^{a}$ \\
\hline $\begin{array}{l}\text { EndoSequence } B C \\
\text { Sealer }\end{array}$ & $5,22 \pm 2,52$ & $5,88 \pm 3,33$ & $4,41 \pm 3,08$ & $6,26 \pm 1,73$ \\
\hline
\end{tabular}

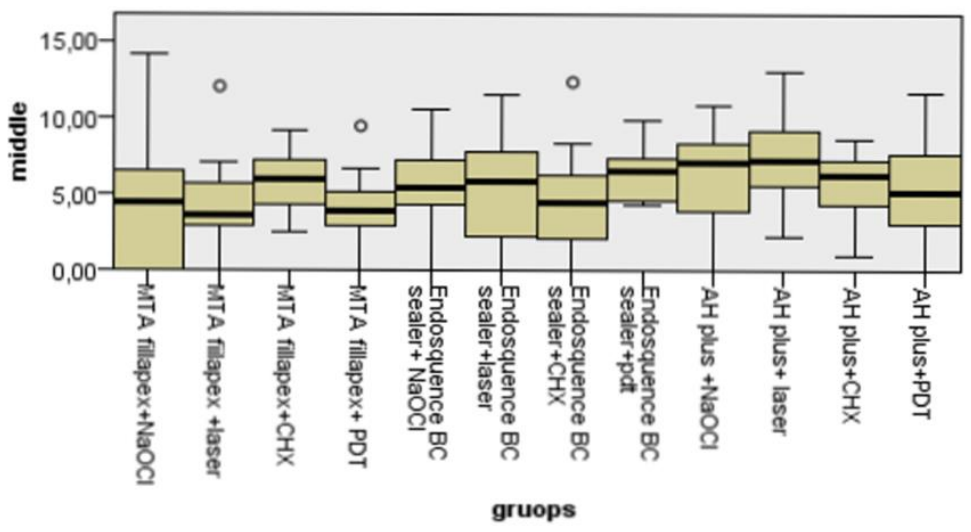

Figure 3. Mean rank value of groups for middle part of root 
Table 3. Median and standard deviation values of coronal part of the root of the groups. Same letters indicate a statistical difference $(\mathrm{P}=0,05)$.

\begin{tabular}{|c|c|c|c|c|}
\hline & $\mathrm{NaOCl}$ irrigation & $\begin{array}{l}\text { Laser } \\
\text { disinfection }\end{array}$ & $\begin{array}{l}\mathrm{CHX} \\
\text { Irrigation }\end{array}$ & $\begin{array}{l}\text { PDT } \\
\text { Disinfection }\end{array}$ \\
\hline AH plus & $4,88 \pm 4,80^{\mathrm{a}}$ & $8,38 \pm 4,63$ & $6,93 \pm 3,58$ & $11,00 \pm 4,42^{\mathrm{a}}$ \\
\hline MTA Fillapex & $4,05 \pm 2,61$ & $5,61 \pm 6,61$ & $5,65 \pm 5,81^{\mathrm{a}}$ & $4,43 \pm 2,88^{\mathrm{a}}$ \\
\hline $\begin{array}{l}\text { EndoSequence } \mathrm{BC} \\
\text { Sealer }\end{array}$ & $6,80 \pm 8,68$ & $7,32 \pm 4,52$ & $5,41 \pm 4,04$ & $8,68 \pm 5,56$ \\
\hline
\end{tabular}

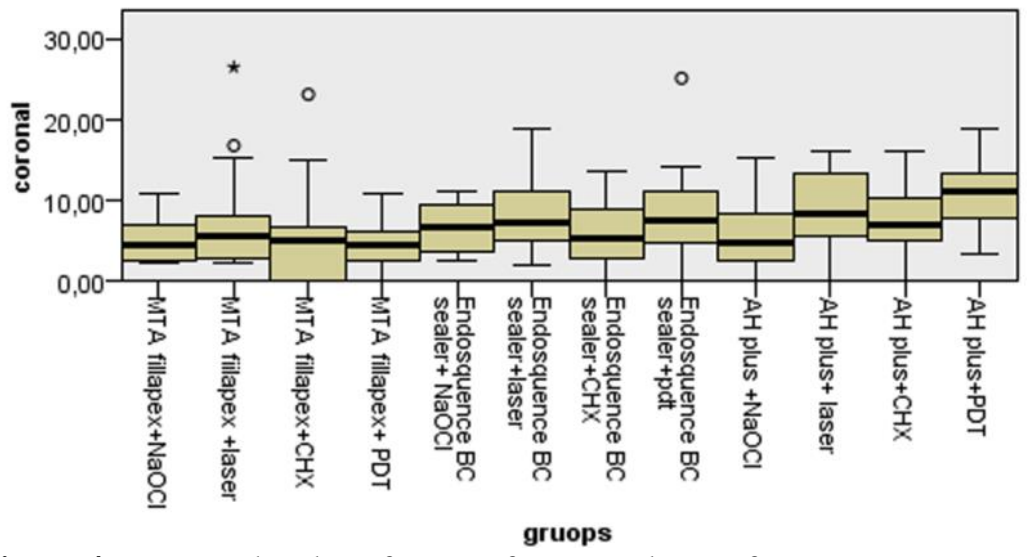

Figure 4. Mean rank value of groups for coronal part of root

For middle part of the root; there was statistically significant relationship between AH plus+ laser disinfection group, MTA Fillapex +PDT disinfection group $(\mathrm{P}=0,014), \quad \mathrm{MTA}$ Fillapex $+\mathrm{NaOCl}$ disinfection group $(\mathrm{P}=0,024)$, MTA + laser disinfection group $(\mathrm{P}=0,037)$ (Table 2) (Figure 3).

For coronal part of the root; there was statistically significant relationship between Ah plus+ PDT disinfection group and MTA Fillapex + PDT disinfection group $(\mathrm{P}=0,004)$, disinfection group and MTA Fillapex + CHX disinfection group $(\mathrm{P}=0,011)$, disinfection group and MTA Fillapex $+\mathrm{NaOCl}$ disinfection group $(\mathrm{P}=0,015)$ (Table 3)(Figure 4).

\section{Discussion}

One of the important stages of endodontic treatment is elimination of microorganisms and their products from root canal system. For this purpose, conventional disinfection methods like irrigation with $\mathrm{NaOCl}$ and $\mathrm{CHX}$, are used. However, these irrigations may inadequate because of microorganisms and their products in lateral canals, isthmus, apical branches, and depth of dentinal tubules (Haapasalo et al. 2010; Haapasalo et al. 2014). PDT and laser systems can support to overcome this challenge (Plotino et al. 2019; Saydjari et al. 2016). Mentioned systems change the permeability, chemical and structural composition of root canal dentin, and this may affect the sealing ability of the root canal sealers (Ok et al. 2013, 2014).
Root canal shaping procedures produce a layer made of inorganic and organic tissue known as smear layer. It includes necrotic pulp remnants, microorganisms and their products. Smear layer can cause pathway for microbial micro-leakage, sheltering bacteria, reservoir of irritants, prevent the penetration of root canal sealers. Therefore, it should remove before filling the root canal (El-Ma'aita et al. 2013). Because of this reason, smear layer was removed to evaluate the sealing ability of the root canal sealers to the dentin in the present study.

Sagsen et al. 2011 compared push out bound strength values of ah plus, I root sp, mta fillapex in the root canals filled with lateral compaction technique after $2,5 \% \mathrm{NaOCl}$ and $17 \%$ EDTA irrigation. They found that there wasn't significant difference in coronal parts of the roots. However, push out bound strength value of mta fillapex was lower than ah plus and I root $\mathrm{sp}$ in the middle and apical sections of the roots. Ok et al. 2014 filled root canals with lateral compaction technique after 5,25\% $\mathrm{NaOCl}$ and $17 \%$ EDTA irrigation then compared push out bound strength values of AH plus and MTA fillapex in their study. They reported that there wasn't significant difference between the push out bond strength values of AHplus and mta fillapex. Additionaly, Shokouhinejad et al. 2013 reported that the bond strength value of EndoSequence BC Sealer was compared to AH Plus in case of presence and absence of smear layer. They found that dislocation resistance of EndoSequence $\mathrm{BC}$ Sealer was equal to $\mathrm{AH}$ Plus and no significant 
effect of the smear layer. Similarly, in our study presented that there weren't significant differences among the AH plus, MTA fillapex, and EndoSequence $\mathrm{BC}$ Sealers in $\mathrm{NaOCl}$ irrigation groups.

Ok et al. 2013 filled root canals with AH plus after $5,25 \% \mathrm{NaOCl}$ irrigation, $2 \% \mathrm{CHX}$ gluconate irrigation, and PAD disinfection systems in their study. They reported that there wasn't significant difference among the push out bond strength values of $\mathrm{AH}$ plus according to disinfection systems. The results of this study are parallel to our study results.

Ok et al. 2014 presented that PAD disinfection method affects adversely the push out bond strength of MTA Fillapex endodontic sealer. In our study found it as the lowest bond strength value of MTa fillapex + PDT groups. But this result wasn't statistically significant. The difference between the results of the studies can be caused by tip of laser and photo sensitizer.

According to the best of our knowledge, there aren't studies about the effect of PDT on bond strength of EndoSequence BC Sealer in literature. Therefore, we couldn't compare.

According to current literature, laser application increases penetration and bond strength values of sealers (Das et al. 2013; Ayrancı and Koseoğlu 2014). A few studies presented that bond strength of sealers using with Nd:YAG laser better than diod laser (Araujo et al. 2018)(Das et al. 2013). Özkaçak and Sonat 2015 reported that laser application increased bond strength of resin and bioceramic root canal sealers also the resin root canal sealers had higher push-out bond strength than the bioceramic sealer. The results of this study are parallel to our study results.

Razmi et al. 2016 compared the effect of $\mathrm{NaOCl}$ and $\mathrm{CHX}$ as final irrigation solution. They found that the bond strength of AH-Plus was not affected the irrigant type; however, CHX reduced the bond strength of Endosequence BC sealer. Conversely, Shokouhinejad et al. 2013 reported that using $\mathrm{NaOCl}$ and $\mathrm{CHX}$ as the final irrigation solution has similar effect on bond strength of EndoSequence BC Sealer to dentinal walls. Another study presented that bond strength of $\mathrm{AH}$ plus was negatively affected $\mathrm{NaOCl}$ as the final irrigation solution in contrast to CHX. In our study the effects of $\mathrm{NaOCl}$ and $\mathrm{CHX}$ on bond strength of sealers were similar. To change a single parameter in studies on bond strength can change all results. Therefore, in order to get better results, more review and meta-analysis are needed.

\section{Conclusion}

Under this study limitation, the bonding strength of root canal sealers is influenced by disinfection methods.

Ethics Committee Approval: The Ordu University Clinical Research Ethics Committee approved the protocol of this study. (2016/22).

Peer-review: Externally peer-reviewed.

Author Contributions: Concept- F.C, E.B.C, H.S.T.; Design-F.C, E.B.C, H.S.T.; Supervision-F.C, E.B.C, H.S.T.; Funding-A.I; Materials-A. İ; Data Collection/Data Process-F.C, E.B.C, H.S.T. A. I; Analyze or Comment-F.C, E.B.C, H.S.T.; Literature Scanning- F.C, A.İ, H.S.T; Writer of Paper- F.C, E.B.C; Critical Review- F.C, E.B.C,

Conflict of Interest: The authors have no conflicts of interest related to this study.

Financial Disclosure: This research study was supported by Ordu University Scientific Research Committee (AR-1601).

\section{References}

Araujo, Vanessa Lessa C.; Cruvinel, Pedro Basto; Palma-Dibb, Regina Guenka; Gariba-Silva, Ricardo: In vitro bond strength of an epoxy resinbased root canal sealer to root dentin irradiated with high-power lasers and adhesive interface analyses. Lasers in medical science 2018;33(2):271-277.

Ayranc1, L. Benan; Koseoglu, Mustafa: The evalution of the effects of different irrigating solutions and laser systems on adhesion of resin-based root canal sealers. Photomedicine and laser surgery 2014;32(3):152-159.

Cakici, Fatih; Cakici, Elif Bahar; Ceyhanli, Kadir Tolga; Celik, Ersan; Kucukekenci, Funda Fundaoglu; Gunseren, Arif Onur: Evaluation of bond strength of various epoxy resin-based sealers in oval shaped root canals. BMC oral health 2016;16 (1):106.

Das, Maneesha; Kumar, G. Anil; Ramesh, Sindhu; Garapati, Surendranath; Sharma, Deepak: An in vitro evaluation of microtensile bond strength of resin-based sealer with dentin treated with diode and Nd:YAG laser. The journal of contemporary dental practice 2013;14 (2):183-187. 
El-Ma'aita, Ahmad M.; Qualtrough, Alison J. E.; Watts, David C.: The effect of smear layer on the push-out bond strength of root canal calcium silicate cements. Dental materials: official publication of the Academy of Dental Materials 2013;29 (7):797-803.

Gomes, Brenda P. F. A.; Vianna, Morgana E.; Zaia, Alexandre A.; Almeida, José Flávio A.; SouzaFilho, Francisco J.; Ferraz, Caio C. R.: Chlorhexidine in endodontics. Brazilian dental journal 2013;24 (2):89-102.

Gurgel-Filho, Eduardo Diogo; Leite, Felipe Martins; Lima, Jaírton Benício de; Montenegro, João Paulo Chaves; Saavedra, Flávia; Silva, Emmanuel João Nogueira Leal: Comparative evaluation of pushout bond strength of A MTA-based root canal sealer. Braz. J. Oral Sci. 2014;13 (2):114-117.

Haapasalo, M.; Shen, Y.; Wang, Z.; Gao, Y.: Irrigation in endodontics. British dental journal 2014;216 (6):299-303.

Haapasalo, Markus; Shen, Ya; Qian, Wei; Gao, Yuan: Irrigation in endodontics. Dental clinics of North America 2010;54(2):291-312.

Jafari, Farnaz; Jafari, Sanaz: Composition and physicochemical properties of calcium silicatebased sealers: A review article. Journal of clinical and experimental dentistry 2017;9(10):e1249e1255.

Lee, Ju Kyung; Kwak, Sang Won; Ha, Jung-Hong; Lee, WooCheol; Kim, Hyeon-Cheol: Physicochemical Properties of Epoxy ResinBased and Bioceramic-Based Root Canal Sealers. Bioinorganic chemistry and applications. 2017: 2582849.

Mestieri, Leticia Boldrin; Gomes-Cornélio, Ana Lívia; Rodrigues, Elisandra Márcia; Salles, Loise Pedrosa; Bosso-Martelo, Roberta; GuerreiroTanomaru, Juliane Maria; Tanomaru-Filho, Mário: Biocompatibility and bioactivity of calcium silicate-based endodontic sealers in human dental pulp cells. Journal of applied oral science: revista FOB 2015;23(5):467-471.

Ok, Evren; Ertas, Huseyin; Saygili, Gokhan; Gok, Tuba: Effect of photoactivated disinfection on bond strength of root canal filling. Journal of endodontics 2013;39(11):1428-1430.

Ok, Evren; Ertas, Huseyin; Saygili, Gokhan; Gok, Tuba: Effect of photo-activated disinfection on bond strength of three different root canal sealers. European journal of dentistry 2014;8(1):85-89.
Ozkocak, Ismail; Sonat, Bade: Evaluation of Effects on the Adhesion of Various Root Canal Sealers after Er:YAG Laser and Irrigants Are Used on the Dentin Surface. Journal of endodontics 2015;41 (8):1331-1336.

Plotino, G.; Grande, N. M.; Mercade, M.: Photodynamic therapy in endodontics. International endodontic journal 2019;52(6):760 774.

Razmi, Hasan; Bolhari, Behnam; Karamzadeh Dashti, Negar; Fazlyab, Mahta: The Effect of Canal Dryness on Bond Strength of Bioceramic and Epoxy-resin Sealers after Irrigation with Sodium Hypochlorite or Chlorhexidine. Iranian endodontic journal. 2016;11(2):129-133.

Sagsen, B.; Ustün, Y.; Demirbuga, S.; Pala, K.: Pushout bond strength of two new calcium silicatebased endodontic sealers to root canal dentine. International endodontic journal 2011;44(12):1088-1091.

Saydjari, Yves; Kuypers, Thorsten; Gutknecht, Norbert: Laser Application in Dentistry: Irradiation Effects of Nd:YAG $1064 \mathrm{~nm}$ and Diode $810 \mathrm{~nm}$ and $980 \mathrm{~nm}$ in Infected Root Canals-A Literature Overview. BioMed research international 2016: 8421656.

Schneider, Sam W.: A comparison of canal preparations in straight and curved root canals. Oral Surgery, Oral Medicine, Oral Pathology 1971; 32 (2):271-275.

Shokouhinejad, Noushin; Gorjestani, Hedayat; Nasseh, Allen Ali; Hoseini, Atefeh; Mohammadi, Maryam; Shamshiri, Ahmad Reza: Push-out bond strength of gutta-percha with a new bioceramic sealer in the presence or absence of smear layer. Australian endodontic journal: the journal of the Australian Society of Endodontology Inc. 2013;39(3):102-106.

Souza, S. F. C.; Bombana, A. C.; Francci, C.; Gonçalves, F.; Castellan, C.; Braga, R. R.: Polymerization stress, flow and dentine bond strength of two resin-based root canal sealers. International endodontic journal 2009;42(10): 867-873. 